\title{
Women in Pain
}





\section{Women in Pain \\ Gender and Morbidity in Mexico}

\section{Kaja Finkler}

\section{$\overline{\text { PENN }}$}

University of Pennsylvania Press

Philadelphia 
Copyright (C) 1994 by Kaja Finkler

All rights reserved

Printed in the United States of America

Library of Congress Cataloging-in-Publication Data

Finkler, Kaja.

Women in pain : gender and morbidity in Mexico / Kaja Finkler.

p. $\mathrm{cm}$.

Includes bibliographical references and index.

ISBN o-8122-3243-7. - o-8122-I527-3 (pbk.)

I. Women-Health and hygiene-Mexico. 2. Women-Health and

hygiene-Social aspects-Mexico. 3. Women-Health and hygieneMexico-Case studies. 4. Women-Health and hygiene-Social aspects-Mexico-Case studies. 5. Sex role-Mexico. I. Title.

RAs64.85.Fs6 1994

$6 \mathrm{I} 4.4^{\prime} 272^{\prime} \mathrm{O} 82-\mathrm{dc} 2 \mathrm{O}$

93-32972

CIP

IO $\begin{array}{lllllllll}9 & 8 & 7 & 6 & 5 & 4 & 3 & 2\end{array}$ 
In memory of my mother, an extraordinary woman ahead of her time, and to my father, who perished ahead of his time 
